\title{
The Color of Rice and the Chinese Paradox
}

\author{
Robert A. Gold ${ }^{\mathrm{a}}$ Tamara Modilevsky ${ }^{\mathrm{a}}$ Kellyanne Rose Gold ${ }^{\mathrm{b}}$ \\ a Olive View - UCLA Medical Center, Sylmar, Calif., and ${ }^{b}$ University of Toledo College of Medicine and Life Sciences, \\ Toledo, Ohio, USA
}

Dear Editor,

A recent article by Dong et al. [1] , 'White Rice Intake Varies in Its Association with Metabolic Markers of Diabetes and Dyslipidemia Across Region among Chinese Adults', revealed a peculiar finding in central China: an inverse relationship exists between rice consumption and LDL cholesterol among the people in the central provinces. The Chinese food composition table, as stated in the Discussion Section, did not include brown rice. Our assumption is that this study also did not include red rice. Jiangsu province, which is included in central China, is one of several eastern Chinese provinces where the fermentation of white rice with the species of yeast called Monascus purpureus originated (other provinces include Fujian, Jiangxi, Zhejiang, Shanghai). Red yeast rice is a dietary staple in these provinces to this day. Interestingly, these same provinces have the lowest cardiovascular mortality in China [2-4].

Red rice yeast is a natural source of monacolins, which inhibit cholesterol biosynthesis. Monacolin K, the predominant monacolin in red rice yeast, is identical to prescription lovastatin [5]. Estimates of between 14 and $80 \mathrm{~g}$ of red rice yeast are consumed per person per day in these eastern Chinese provinces $[5,6]$. The quantification of total statin content in traditional red rice yeast food products has not been extensively studied. The FDA reported red rice yeast food products contained small quantities of monacolin $\mathrm{K}$ (lovastatin) or none at all in numerous off-the-shelf sam- ples [7]. This FDA report was not a peerreviewed study but part of an investigation into the status of over-the-counter red rice yeast dietary supplements. One article in the literature that specifically measured total statin content in traditional Chinese red rice yeast for 2 different food products reported 20 and $25 \mu \mathrm{g} / \mathrm{g}$ [6]. These concentrations of total statins are far below those found in commercially available food supplements, but given the range of estimated daily red rice yeast intake, would calculate to 1-2 $\mathrm{mg}$ /day of total statin intake per person. Could this be significant?

Clinical trials of commercially available red rice yeast supplements, prepared under optimal conditions of temperature, $\mathrm{pH}$ and specific Monascus purpureus strain to enhance monacolin $\mathrm{K}$ content (5-10 mg lovastatin per capsule), have demonstrated efficacy in lowering total and LDL cholesterol $[5,8,9]$. One trial reported greater-thanexpected reduction in total and LDL cholesterol based on monacolin $\mathrm{K}$ content [5]. Subjects received supplements with an equivalent of $5 \mathrm{mg}$ /day of monacolin $\mathrm{K}$ (lovastatin) but experienced cholesterol reductions that were similar to lovastatin daily dosages of 20-40 mg [5]. This finding led to the possibility that other components of red rice yeast, which include other statin metabolites and phytosterols, may have additional favorable effects on lipid metabolism [9]. Phytosterols have been demonstrated to have lipid-lowering properties [10]. A randomized secondary prevention trial in China of red rice yeast supplements compared to placebo demonstrated reduction in cardiovascular morbidity and mortality [11].

Therefore, although the other provinces in Central China are not traditionally high utilizers of red rice yeast as a food, it remains a possibility that the inverse relationship of rice intake with LDL cholesterol may be partially explained by the consumption of red rice by the population in the Jiangsu province.

The epidemiological Chinese Paradox regarding the markedly higher incidence of cardiovascular disease in Northern China compared to Southern China [3], although partially explainable by variations in traditional cardiac risk factors [12], may be influenced by red rice yeast intake. The Chinese provinces with the lowest cardiovascular disease mortality have traditionally utilized red rice yeast in their diets. These regions are located along the southeastern coastline. Interestingly, Guangdong, which is just south of the Fujian province, has similarly high cardiovascular mortality as Northern China. Guangdong, which is the center of Cantonese style cuisine, is not known for red rice yeast consumption.

Could a lifetime exposure to red rice yeast and the small amounts of statins and phytosterols that it contains partially explain the reason for the observation of reduced cardiovascular mortality in Chinese provinces consuming red rice yeast? It would certainly be of interest to determine the color of rice in future epidemiological studies.

\section{KARGER}

E-Mail karger@karger.com

www.karger.com/anm (c) 2016 S. Karger AG, Base

0250-6807/16/0682-0128\$39.50/0
Prof. Robert A. Gold

Olive View - UCLA Medical Center

14445 Olive View Drive

Sylmar, CA 91342 (USA)

E-Mail robertgold87@yahoo.com 


\section{References}

1 Dong F, Howard AG, Herring AH, Popkin $\mathrm{BM}$, Gordon-Larsen P: White rice intake varies in its association with metabolic markers of diabetes and dyslipidemia across region among Chinese adults. Ann Nutr Metab 2015; 66:209-218

2 Wu Z, Yao C, Zhao D, Wu G, Wang W, Liu J, et al: Sino-MONICA project: a collaborative study on trends and determinants in cardiovascular diseases in China, part I: morbidity and mortality monitoring. Circulation 2001; 103:462-468.

3 Huang J, Wu YF, Liu XQ, Ding D, Zhao LC, $\mathrm{Lu} \mathrm{B}$, et al: Subclinical atherosclerosis in northern and southern China: the Chinese paradox. J Geriatr Cardiol 2011;8:72-77.

4 Zheng Y, Stein R, Kwan T, Yu C, Kwan J, Chen SL, et al: Evolving cardiovascular disease prevalence, mortality, risk factors, and the metabolic syndrome in China. Clin Cardiol 2009;32:491-497.
5 Heber D, Yip I, Ashley JM, Elashoff DA, Elashoff RM, Go VL: Cholesterol-lowering effects of a proprietary Chinese red-yeast-rice dietary supplement. Am J Clin Nutr 1999;69: 231-236.

6 Mornar A, Sertić M, Nigović B: Development of a rapid LC/DAD/FLD/MS(n) method for the simultaneous determination of monacolins and citrinin in red fermented rice products. J Agric Food Chem 2013;61:1072-1080.

7 US Department of Health and Human Services FDA: Pharmanex, Inc., Administrative Proceeding, Docket No. 97P-0441, Final Decision, May 20, 1998.

8 Becker DJ, Gordon RY, Halbert SC, French B, Morris PB, Rader DJ: Red yeast rice for dyslipidemia in statin-intolerant patients: a randomized trial. Ann Intern Med 2009;150: 830-839, W147-W149.

9 Lin CC, Li TC, Lai MM: Efficacy and safety of Monascus purpureus went rice in subjects with hyperlipidemia. Eur J Endocrinol 2005; 153:679-686
10 Hendriks HF, Weststrate JA, van Vliet T, Meijer GW: Spreads enriched with three different levels of vegetable oil sterols and the degree of cholesterol lowering in normocholesterolaemic and mildly hypercholesterolaemic subjects. Eur J Clin Nutr 1999;53:319327.

11 Lu Z, Kou W, Du B, Wu Y, Zhao S, Brusco OA, et al: Effect of Xuezhikang, an extract from red yeast Chinese rice, on coronary events in a Chinese population with previous myocardial infarction. Am J Cardiol 2008; 101:1689-1693.

12 Gu D, Gupta A, Muntner P, Hu S, Duan X, Chen J, et al: Prevalence of cardiovascular disease risk factor clustering among the adult population of China: results from the International Collaborative Study of Cardiovascular Disease in Asia (InterAsia). Circulation 2005; 112:658-665. 